\title{
Carcinoma urotelial renal en una paciente con enfermedad renal poliquística autosómico dominante: Presentación de un caso y revisión de la literatura
}

\author{
Arce Terroba $\mathrm{Y}^{*}$, Martí $\mathrm{T}^{* *}$, Villavicencio Mavrich $\mathrm{H}^{* * *}$, De la Torre $\mathrm{P}^{* *}$, Algaba $\mathrm{F}^{*}$. \\ *Sección de Anatomía Patológica. **Servicio de Radiología. ${ }^{* * *}$ Servicio de Urología. Fundació Puigvert. \\ Barcelona.
}

Actas Urol Esp. 2007;31(10):1182-1188

\section{RESUMEN}

CARCINOMA UROTELIAL RENAL EN UNA PACIENTE CON ENFERMEDAD RENAL POLIQUÍSTICA AUTOSÓMICO DOMINANTE: PRESENTACIÓN DE UN CASO Y REVISIÓN DE LA LITERATURA

Presentamos un caso de carcinoma urotelial de pelvis renal en una paciente de 48 años con enfermedad renal poliquística autosómico dominante (ERPAD). Se discute la dificultad del diagnóstico radiológico en estos pacientes y se revisa la incidencia de tumores renales en dicha entidad. La asociación de carcinoma urotelial y ERPAD es muy infrecuente y aparentemente sin relación causal.

Palabras clave: Carcinoma urotelial. Enfermedad renal poliquística autosómica dominante.

\section{ABSTRACT}

UROTHELIAL CARCINOMA IN A WOMAN WITH AUTOSOMAL DOMINANT POLYCYSTIC KIDNEY DISEASE: DESCRIPTION OF A CASE AND REVISION OF THE LITERATURE

We describe a case of urothelial carcinoma of renal pelvis in a 48 years old woman affected of autosomal dominant polycystic kidney disease (ADPKD). We discuss the difficulty of the radiological diagnostic and we revise the incidence of renal tumors in this entity. Association between urothelial carcinoma and ADPKD is highly infrequent and without apparently causal relation.

Keywords: Urothelial carcinoma. Autosomal dominant polycystic kidney disease.

$\mathrm{L}$ a detección clínico-radiológica de masas renales en pacientes con ERPAD es más complicada debido a la alteración intrínseca de la arquitectura renal en estos pacientes. La coincidencia de un carcinoma urotelial de pelvis renal en un paciente con enfermedad renal poliquística autosómico dominante (ERPAD) es muy infrecuente. Presentamos las características clínicas, radiológicas y anatomo-patológicas de este caso excepcional.

\section{CASO CLÍNICO}

Mujer de 48 años, fumadora de 20 cigarrillos/día, con poliquistosis hepatorrenal diagnosticada 12 años antes, y enfermedad renal crónica secundaria estadio 3 (con aclaramiento creatinina de $50 \mathrm{ml} / \mathrm{min}$ y sin proteinuria). Sin ningún otro antecedente patológico de interés. La enfermedad actual comienza con dolor lumbar izquierdo intenso que requiere ingreso. Inicialmente se orienta como crisis quística.

Se realiza ecografia reno-vesical (Fig. 1) en la que, en el contexto de poliquistosis hepatorrenal, se aprecia una desestructuración parenquimatosa renal por quistes, preferentemente en el lado izquierdo, con aumento del tamaño respecto al contralateral, Existe una ecogenicidad heterogénea en el parénquima preservado que sugiere turgencia parenquimatosa y se observa desdibujamiento sinusal izquierdo secundario a presencia de un tejido ecogénico que ejerce efecto de masa y se proyecta hacia la pelvis renal. Dada la 
poca especificidad de los hallazgos ecográficos se completa el estudio mediante TC (Fig. 2) que muestra nuevamente desestructuración renal bilateral por poliquistosis, con algunos quistes hiperdensos en el estudio basal realizado sin contraste endovenoso. La afectación es asimétrica, más intensa en el lado izquierdo, siendo dicho riñón de mayor tamaño. La región piélica izquierda está ocupada por un tejido de densidad de partes blandas que muestra un realce moderado tras la administración endovenosa de contraste, sin definición clara de sus límites. Funcionalmente existe un evidente retraso en el lado izquierdo y ausencia de eliminación del contraste endovenoso en las secciones realizadas de forma retardada. El conjunto de hallazgos sugiere ocupación tumoral de la pelvis renal en el contexto de poliquistosis con alteración funcional secundaria. Se observan ganglios retroperitoneales no aumentados significativamente de tamaño en situación interaortocava y retroaórtica.

Con el diagnóstico clínico de masa renal compatible con proceso neoformativo, se realiza nefrectomía radical izquierda, con suprarrenalectomía izquierda más linfadenectomía aortocava, sin incidencias ni complicaciones inmediatas. En el postoperatorio no surgen complicaciones, con función renal estable. Un mes después de la nefrectomía, el aclaramiento de creatinina fue de $52 \mathrm{ml} / \mathrm{min}$ y aparece proteinuria de 0,16 g/24 h.

En el estudio anátomo-patológico de la pieza, macroscópicamente destaca una masa renal

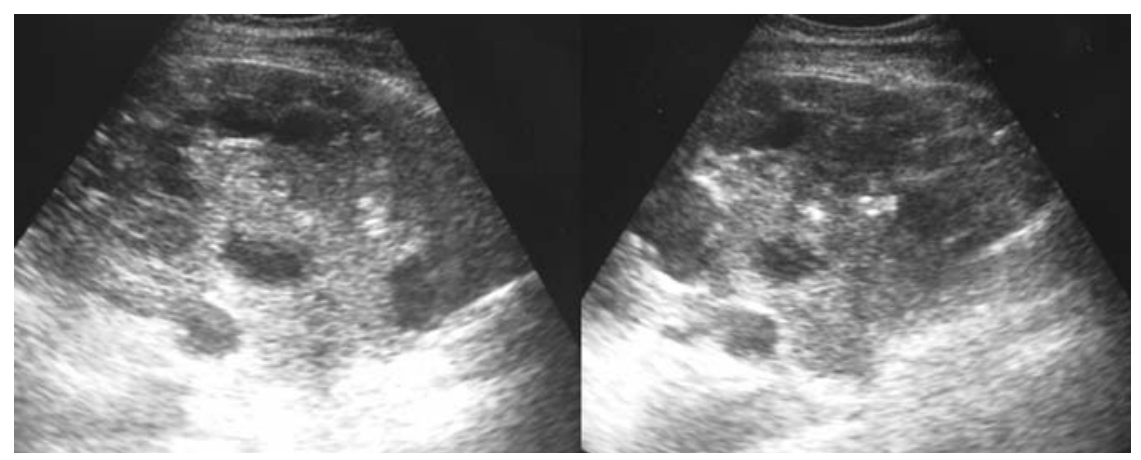

FIGURA 1. Imágenes ecográficas que muestran la presencia de tejido ecogénico en el seno renal que ejerce efecto de masa y se proyecta hacia la pelvis renal.

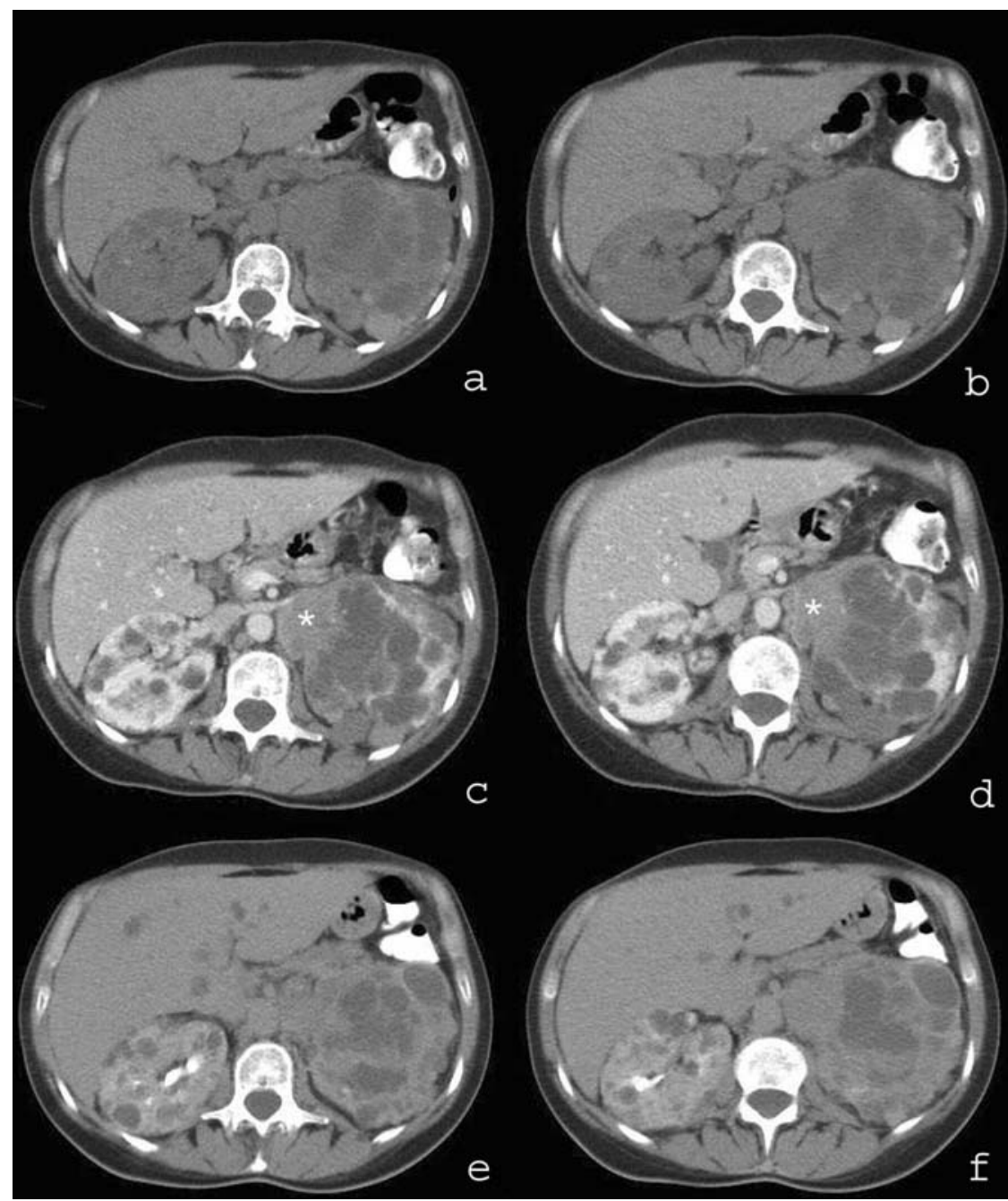

FIGURA 2. En las secciones tomográgicas realizadas previa a la administración de contraste $(a, b)$ se aprecia la afectación asimétrica por poliquistosis de ambos riñones asi como la asimetría de tamaño renal. El seno renal aparece ocupado por un tejido de partes blandas que después de administrar contraste (c,d) muestra realce (asteriscos). En las secciones realizadas de forma retardada $(e, f)$ no se observa excreción de contraste en el lado izquierdo. 
blanquecina, firme, de $9 \times 8,5 \times 5 \mathrm{~cm}$., de bordes mal definidos, que presenta un área central de necrosis (Fig. 3A). Está situada en la porción central renal, afectando la práctica totalidad del parénquima, alcanzando el tejido adiposo perirrenal y rodeando la glándula suprarrenal. En el hilio renal se identifican cuatro ganglios linfáticos. El parénquima renal no tumoral está totalmente desestructurado y sustituido por múltiples quistes de hasta $2 \mathrm{~cm}$ de diámetro, y que afectan tanto corteza como médula renal. Histológicamente, la tumoración está constituida por células de citoplasma amplio y eosinófilo, con núcleos redondeados con marcada atipia, que se organizan en un patrón sólido cohesivo, característico de un carcinoma escamoso pobremente diferen- ciado (Fig. 4B). Son extensas las áreas de necrosis tumoral. El tumor afecta uréter proximal, pelvis renal, parénquima renal y tejido adiposo (Fig. 4C) tanto perirrenal como perihiliar. Se objetiva infiltración tumoral de la vena renal y extensa infiltración tumoral perineural (Fig. 4D) con afectación de ganglios simpáticos del hilio renal. La masa tumoral está constituida por carcinoma escamoso, en el seno de la cual, se aprecia un área de carcinoma urotelial papilar intraureteral (Fig. 4A). Se identifica metástasis del carcinoma en dos de los cuatro ganglios linfáticos hiliares identificados en la pieza. Los márgenes de resección quirúrgica de la pieza, son negativos. En la linfadenectomía paraórtica se identifican 6 ganglios linfáticos libres de infiltración neoplásica.
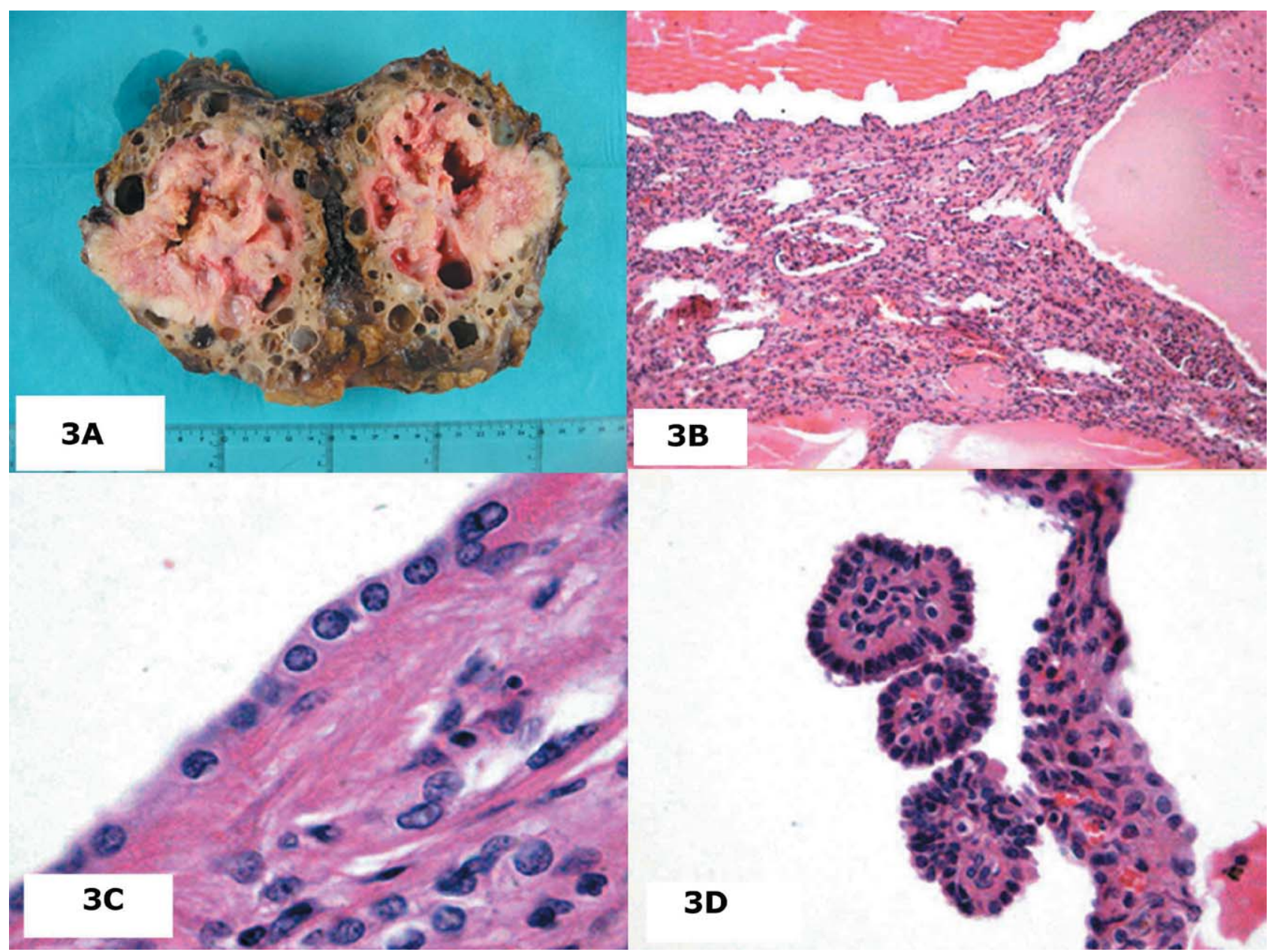

FIGURA 3. 3A. Sección longitudinal de la pieza de nefrectomía donde se observa, en la porción central, un tumor blanquecino con áreas sólidas periféricas y centro necrótico con quistificación. El parénquima renal no tumoral está desestructurado y sustituido por múltiples quistes. 3B. Sección del parénquima renal no tumoral, donde se observan quistes renales con parénquima preservado entre ellos. 3C. Detalle del epitelio cúbico que tapiza los quistes. 3D. Proliferación papilar intraquistica. 


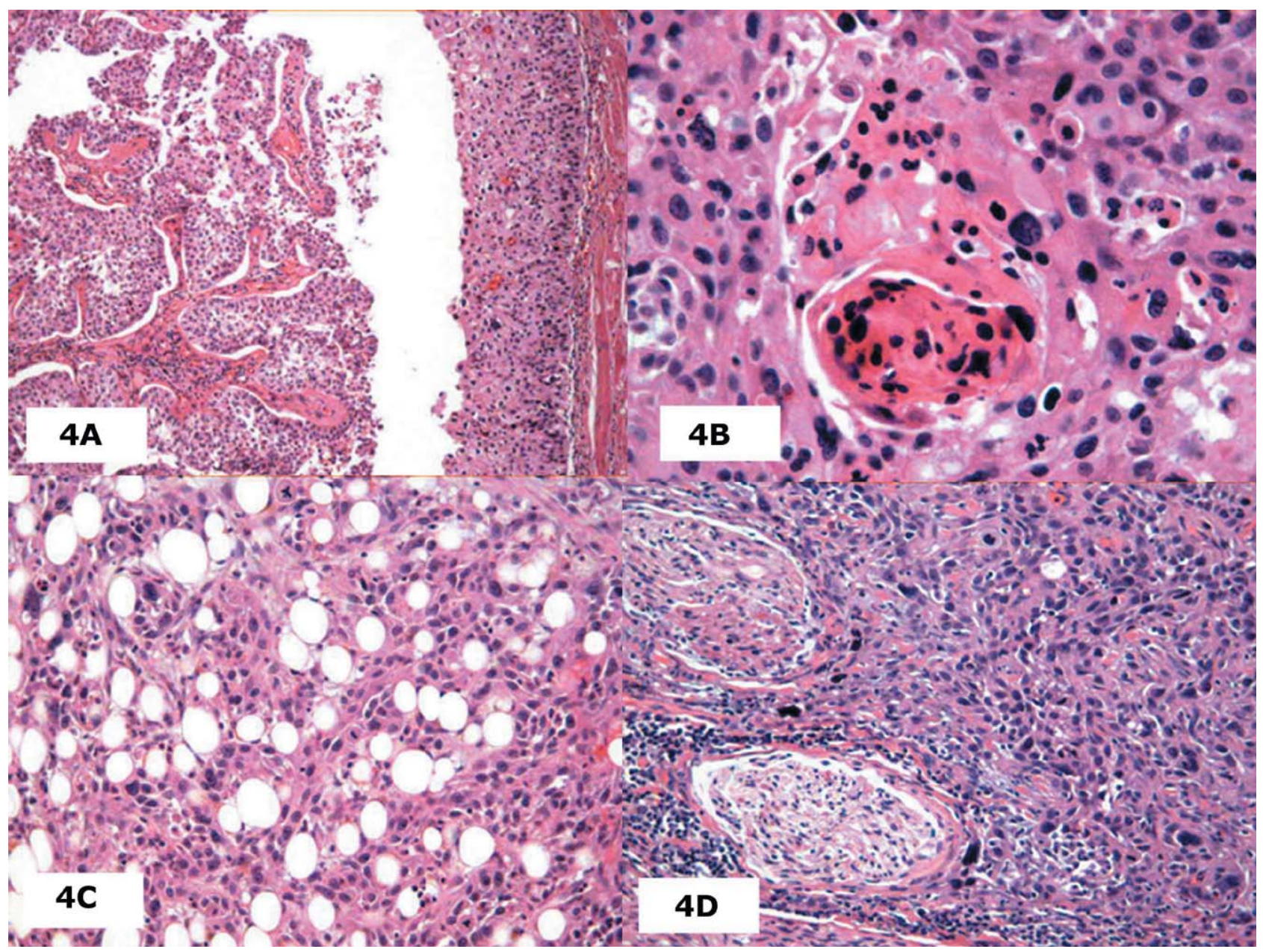

FIGURA 4. 4A) Carcinoma urotelial papilar de alto grado intraureteral. 4B) Área de diferenciación escamosa con gran atipia celular y queratinización. 4C) Infiltración tumoral del tejido adiposo perirrenal. 4D) Infiltración perineural tumoral.

En resumen, el diagnóstico anátomo-patológico de la pieza es de carcinoma escamoso pobremente diferenciado originado en pelvis renal y uréter, categoría pT4pN2, en el contexto de enfermedad renal poliquística autosómico-dominante (riñón poliquístico del adulto).

En la actualidad, la paciente sigue tratamiento oncológico.

\section{DISCUSIÓN}

La ERPAD está englobada en el heterogéneo grupo de enfermedades renales que se caracterizan por la presencia de numerosos quistes en el parénquima renal $^{1}$. También se conoce con el nombre de riñón poliquístico del adulto ya que aunque puede manifestarse a cualquier edad, suele hacerlo durante la etapa adulta. Es una enfermedad que generalmente se hereda como un rasgo dominante, aunque puede surgir como una mutación espontánea. Es debida en un $85 \%$ de los casos a la alteración del gen 1 de la enfermedad renal poliquística (PKD1) que codifica para la policistina 1 y está situado en el cromosoma 16 . También puede deberse a la alteración del PKD2 que codifica para la policistina 2 y está situado en el cromosoma 4, y a la alteración del PKD3 que codifica para la policistina $3^{1}$. Las manifestaciones clínicas son debidas al agrandamiento de los quistes e incluyen pesadez y dolor lumbar, hematuria, fallo renal progresivo, hipertensión arterial y litiasis renal. La ERPAD puede tener manifestaciones extrarrenales como quistes hepáticos (como en el caso que presentamos), quistes pancreáticos y meníngeos, aneurismas coronarios y cerebrales, prolapso mitral y anomalías en las valvas aórticas. 
Macroscópicamente, los riñones afectos se caracterizan por la presencia de múltiples quistes esféricos, de entre 0,5 y $5 \mathrm{~cm}$. de diámetro, que afectan tanto a córtex como a médula renal. Histológicamente, los quistes están revestidos por una monocapa de células cuboideas o columnares (Fig. 3C). Con frecuencia se observan proliferaciones de estas células que pueden formar proyecciones papilares intraquísticas (Fig. 3D) ${ }^{1}$.

En general los pacientes con la enfermedad tienen quistes ya detectables por ecografía hacia los 30 años de edad. Múltiples quistes macroscópicos se visualizan en todo el grosor del parénquima renal. A medida que la enfermedad progresa, los riñones aumentan de tamaño y los quistes ven incrementado su número y dimensión hasta que sustituyen al parénquima renal. La enfermedad suele ser simétrica y raras veces sólo un riñón muestra enfermedad significativa, siendo este hecho más frecuente en la edad pediátrica $^{2}$. La mayoría de los quistes tienen un aspecto típico cuando se estudian con las distintas técnicas de imagen, siendo por ecografía anecoicos con refuerzo acústico posterior, hipodensos sin realce significativo tras la administración endovenosa de contraste yodado por TC, y se muestran hipointensos en secuencias potenciadas en $\mathrm{T} 1$, hiperintensos en secuencias potenciadas en T2, y no realzan tras administrar contraste paramagnético cuando se estudian por RM.

En casi todos los casos se pueden observar quistes hemorrágicos con ecos intraquísticos por ultrasonido, alto coeficiente de atenuación en TC no contrastado que en general será homogéneo, pero que puede presentarse en forma de capas creando niveles líquido-líquido. Cuando se estudian por RM los quistes hemorrágicos presentarán una intensidad de señal variable en las distintas secuencias, dependiendo de la cronología del sangrado ${ }^{3}$.

Complicaciones como litiasis renales o calcificaciones quísticas son frecuentes ${ }^{4}$. La infección de alguno de los quistes es otra complicación que por sus características en imagen -quistes con densidad discretamente superior al agua con engrosamiento de paredes y captación de contraste, asociado o no a alteraciones inflamatorias peri o pararrenales ${ }^{5}$ debe ser incluida en el diagnóstico diferencial con un proceso neoformativo.
Se ha demostrado un mayor número de neoplasias renales en pacientes con ERPAD, la mayoría adenomas microscópicos de limitado significado clínico ${ }^{6}$. Aunque no se ha podido demostrar una mayor incidencia de carcinoma renal en ERPAD ${ }^{6-8}$, cuando éste se desarrolla, tiene un comportamiento diferente que en la población general, de forma que aparece en edades más jóvenes, con más frecuencia es bilateral, multicéntrico y de tipo sarcomatoide ${ }^{7}$. El riesgo de desarrollar carcinoma renal es mayor en los pacientes con ERPAD con insuficiencia renal que requiere hemodiálisis, ya que es entonces cuando se desarrolla la enfermedad renal quística adquirida, que sí tiene un mayor riesgo de desarrollar carcinoma renal ${ }^{1,9}$.

Cuando existe un carcinoma renal los criterios diagnósticos por imagen ${ }^{10}$ son similares al resto de población general, si bien el diagnóstico vendrá dificultado en mayor o menor medida por el grado de desestructuración parenquimatosa. Un quiste denso que se realce con el contraste o la presencia de tejido de partes blandas intraquístico que también realce deberá hacernos sospechar un proceso neoplásico. El desarrollo de carcinoma urotelial renal en pacientes con ERPAD es muy infrecuente. La presencia de una masa en la vía urinaria de ecogenicidad tisular que en TC realce con el contraste también orientará hacia el diagnóstico de carcinoma urotelial $^{11}$.

De los casos descritos previamente en la literatura anglosajona, uno de ellos se desarrolló en un paciente en hemodiálisis de larga evolución ${ }^{12}$, otro está asociado a tumor vesical ${ }^{13}$, y el tercero ${ }^{6}$ fue un pequeño tumor superficial. El primer caso descrito, aparece en la clásica revisión de Gregoire et al. ${ }^{6}$ donde establecen que los pacientes con ERPAD no tienen mayor riesgo de desarrollar carcinoma renal que la población general. En su revisión de 87 riñones de pacientes con ERPAD, sólo encuentran un caso de carcinoma urotelial, en una mujer de 58 años sin historia de diálisis. En el artículo no queda explicitado si se trata de un caso de autopsia o quirúrgico, pero en cualquier caso, las imágenes y la descripción del caso corresponden con un tumor superficial de bajo grado y de pequeño tamaño. El segundo caso descrito ${ }^{12}$, es el de una mujer de 81 años 
con historia de hemodiálisis durante 26 años por insuficiencia renal crónica secundaria a ERPAD. Histológicamente, se demostró un carcinoma urotelial papilar, grado II, categoría pTa en pelvis renal. El tercer caso $^{13}$, es el de una mujer de 44 años, con historia de ERPAD sin hemodiálisis, en la que histológicamente se demuestra un carcinoma urotelial, grado $2-3 / 4$ de pelvis renal, pT3pN2, asociado a carcinoma urotelial vesical.

Por tanto, según nuestra revisión, el nuestro sería el primer caso de carcinoma urotelial de pelvis renal, con formación de gran masa tumoral, infiltración de parénquima renal y tejido adiposo perirrenal, y con extensa diferenciación escamosa, en una paciente con historia de ERPAD, sin insuficiencia renal y sin historia de hemodiálisis.

El estudio radiológico del caso que presentamos evidencia la dificultad para realizar el diagnostico de carcinoma urotelial de tracto superior dada la desestructuración parenquimatosa existente. En la ecografía se aprecia la presencia de material ecogénico en la pelvis renal que plantea, en contexto clínico de sospecha de crisis quística, la posibilidad que dicha ocupación estuviera producida por coágulos. En las imágenes tomográficas si bien no es posible delimitar la pelvis renal con precisión por la alteración de la arquitectura renal, si podemos afirmar que en su posición teórica existe un tejido de partes blandas que capta contraste, lo que permite descartar una ocupación por coágulos de la vía excretora y orientar hacia una etiología tumoral.

La asimetría del tamaño renal en nuestro caso la atribuimos a la infiltración de la vía urinaria y del parénquima renal por la tumoración, correspondiendo algunas de las formaciones intrarenales de aspecto quístico a dilataciones calicilares. La ausencia de excreción de contraste en las secciones tomográficas realizadas de forma retardada no nos ayuda a distinguir quistes de cálices dilatados ni a delimitar la ocupación tumoral de la luz.

No está establecida cual es la patogénesis del desarrollo de tumores malignos en la ERPAD. En el caso del carcinoma renal de células claras, se especula que éste puede originarse en los focos de hiperplasia papilar intraquística ${ }^{1,6}$. En el caso del carcinoma urotelial, no está establecido cual es su relación, si es que la hay, con la ERPAD. Se han propuesto varias hipótesis ${ }^{12}$ : En primer lugar, que el gen de la enfermedad poliquística, que se cree responsable de la proliferación de las células epiteliales y de la formación de quistes, puede ser también causante del carcinoma urotelial. En contra de esta teoría, está el hecho de que la ERPAD y el carcinoma renal están en relación a alteraciones del epitelio tubular, y no del epitelio transicional, como sería el caso del carcinoma urotelial $^{13}$. En segundo lugar, se ha propuesto que la inflamación crónica de quistes infectados o de infecciones urinarias pueda provocar alteraciones en las células uroteliales que lleven a la transformación neoplásica ${ }^{12}$. De los cuatro casos que hemos descrito, en dos no constan episodios infecciosos y en los otros dos (incluyendo el nuestro) no hay dicho antecedente. Por tanto, si bien no se puede rechazar completamente esta opción, la infección no es un factor necesario en la trasformación neoplásica del urotelio en la ERPAD. Otra teoría sería que el ambiente urémico sea un factor promotor del carcinoma urotelial ${ }^{12}$. El hecho de que de los cuatro casos descritos sólo uno tuviera historia de hemodiálisis hace poco probable esta opción. Por último, una posible explicación sería que factores etiológicos potenciales en el carcinoma urotelial (el tabaquismo en nuestro caso) serían exacerbados por las complicaciones propias de la ERPAD, como son la exposición prolongada a los carcinógenos urinarios debidos a la obstrucción o inflamación asociados con infección o litiasis $^{13}$. En contra de esta opción, y tal como hemos visto en nuestra revisión, no se ha descrito un aumento de la incidencia de carcinoma urotelial en pacientes con ERPAD con respecto a la población general.

\section{CONCLUSIÓN}

Estudios previos han demostrado que la ERPAD no comporta mayor riesgo en el desarrollo de un carcinoma renal. Por otra parte, tampoco hemos hallado datos en la literatura que indiquen que la ERPAD comporte mayor riesgo en el desarrollo de carcinoma urotelial. En aquellos casos en que coexisten ambas patologias, la marcada alteración de la arquitectura renal dificulta el diagnóstico clínico-radiológico. 


\section{REFERENCIAS}

1. D’Agati VD, Jenette JC, Silva FG. Congenital abnormalities including cystic diseases. West King D. Editor. Non neoplastic kidney diseases. Atlas of nontumor pathology. First series. Fascicle 4. Maryland. Silver Spring, 2005, pp 32-37.

2. Fick-Brosnahan G, Johnson AM, Strain JD, Gabow PA. Renal asymmetry in children with autosomal dominant polycystic kidney disease. Am J Kidney Dis. 1999;34(4): 639-645.

3. Mosetti MA, Leonardou P, Motohara T, Kanematsu M, Armao D, Semelka RC. Autosomal dominant polycystic kidney disease: MR imaging evaluation using current techniques. J Magn Reson Imaging. 2003;18(2):210-215.

4. Levine E, Grantham JJ. Calcified renal stones and cyst calcifications in autosomal dominant polycystic kidney disease: clinical and CT study in 84 patients. AJR Am J Roentgenol. 1992;159(1):77-81.

5. Gupta S, Seith A, Sud K, Kohli HS, Singh SK, Sakhuja V,et al. CT in the evaluation of complicated autosomal dominant polycystic kidney disease. Acta Radiol. 2000;41(3):280-284.

6. Gregoire JR, Torres VE, Holley KE, Farrow GM. Renal epithelial hiperplastic and neoplastic proliferation in autosomal dominant polycystic Kidney disease. Am J Kid. Dis. 1987;9(1):27-38.

7. Keith DS, Torres VE, King BF, Zincki H, Farrow GM. Renal cell carcinoma in autosomal dominant polycystic kidney disease. J Am Soc Nephrol. 1994;4:1661-1669.

8. Sulser T, Fehr JL, Hailemariam S, Briner J, Hauri D. Papillary renal cell carcinoma associated with autosomal dominant polycystic kidney disease. Urol Int. 1993;51(3): 164-166.
9. Gataliza Z, Schwarting R, Petersen RO. Renal cell carcinoma in the presence of adult polycystic kidney disease. Urology. 1994;43(1):102-105.

10. Israel GM, Bosniak MA. How I do it: evaluating renal masses. Radiology. 2005;236(2):441-450.

11. Rabii R, el Mejjad A, Fekak H, Querfani B, Joual A, el Mrini M. Tumeur des vois excrétrices superieures sur polykystose rénale. Progrès en urologie, 2003;13(4):686-689.

11. Rabii R, el Mejjad A, Fekak H, Querfani B, Joual A, el Mrini M. Tumor of upper urinary tract in renal polycystic disease. Prog Urol. 2003;13(4):686-689.

12. Miwa S, Fuse H, Hirano S, Masuda S. Transitional cell carcinoma of the renal pelvis in a long-term hemodialysis patient with autosomal dominant polycystic kidney. Int $\mathrm{J}$ Urol. 2001;8(10):572-574.

13. Grubb RL 3rd, Collyer WC, Kibel AS. Transitional cell carcinoma of the renal pelvis associated with hypercalcemia in a patient with autosomal dominant polycystic kidney disease. Urology. 2004;63(4):778-780.

Correspondencia autora: Dra. Y. Arce Terroba Anatomía Patológica. Fundación Puigvert

Cartagena, 340 - 08025 Barcelona

Tel.: 934169700 ext. 1112

E-mail autora: yarce@fundacio-puigvert.es

Información artículo: Nota clínica

Trabajo recibido: junio 2006

Trabajo aceptado: julio 2006 